\title{
Clinical and genetic characteristics of Dutch children with central congenital hypothyroidism, early detected by neonatal screening
}

\author{
J C Naafs 1,2, P H Verkerk ${ }^{3}$, E Fliers ${ }^{2}$, A S P van Trotsenburg' ${ }^{1}$ and \\ N Zwaveling-Soonawala'
}

'Department of Pediatric Endocrinology, Emma Children's Hospital, Amsterdam UMC, University of Amsterdam, Amsterdam, The Netherlands, ${ }^{2}$ Department of Endocrinology and Metabolism, Amsterdam UMC, University of Amsterdam, Amsterdam Gastroenterology Endocrinology \& Metabolism, Amsterdam, The Netherlands, and ${ }^{3}$ TNO, Department of Child Health, Leiden, The Netherlands

Correspondence should be addressed to N Zwaveling-Soonawala Email n.zwaveling@ amsterdamumc.nl

\begin{abstract}
Objective: To evaluate clinical characteristics of patients with central congenital hypothyroidism $(\mathrm{CH})$, detected in the Dutch neonatal screening program. This included patients with isolated central $\mathrm{CH}$ but the majority have multiple pituitary hormone deficiencies (MPHD).

Design: Nationwide, cross-sectional study.

Methods: Data was collected on clinical characteristics, endocrine tests and neuroimaging of central CH patients, detected by the Dutch neonatal screening and born between 1 January 1995 and 1 January 2015. Height and pubertal status were assessed during a study visit. Isolated central $\mathrm{CH}$ patients without a confirmed genetic diagnosis were offered genetic (re-)testing.

Results: During the 20-year period 154 central CH patients were detected (incidence of permanent central CH 1:25 642). After excluding deceased (15), severe syndromic (7) and transient patients (6), 92 of 126 eligible patients were included (57 MPHD; 79\% male). Sixty-one patients (50 MPHD) had been hospitalized before screening results were reported, but central $\mathrm{CH}$ was diagnosed on clinical grounds in only three of them (5\%). MRI abnormalities consistent with pituitary stalk interruption syndrome were seen in 50 (93\%) MPHD patients. Among isolated central CH patients, 27 (84\%) had an IGSF1, TBL1X or IRS4 gene variant (53, 16 and $16 \%$, respectively).

Conclusion: Many patients with central $\mathrm{CH}$ have neonatal health problems, especially MPHD patients. Despite hospital admission of two-thirds of patients, almost none were diagnosed clinically, but only after the notification of an abnormal screening result was received. This indicates that central $\mathrm{CH}$, especially if isolated, is an easily missed clinical diagnosis.
\end{abstract}

\section{Introduction}

Central congenital hypothyroidism $(\mathrm{CH})$ is characterized by thyroid hormone deficiency at birth due to insufficient hypothalamic-pituitary stimulation of a normal thyroid gland $(1,2)$. Central $\mathrm{CH}$ may occur in isolation, but is (c) 2020 European Society of Endocrinology Printed in Great Britain often accompanied by multiple pituitary hormone deficiencies (MPHD) $(3,4)$.

As $\mathrm{CH}$ is harmful to brain growth and development, neonatal screening for $\mathrm{CH}$ has been implemented 
worldwide since the 1970s. These screening programs are effective in early detection and treatment of $\mathrm{CH}$ and, with that, in the prevention of neurodevelopmental disabilities.

Because primary $\mathrm{CH}$, i.e. $\mathrm{CH}$ of thyroidal origin, is more prevalent than central $\mathrm{CH}$, most screening programs focus on detecting primary $\mathrm{CH}$, and only measure thyrotropin (TSH) (5). Very few countries employ a thyroxine (T4) or free T4-based screening that also detects central $\mathrm{CH}(6,7)$. Whether detecting central $\mathrm{CH}$ should be a screening goal remains a topic of debate. However, it is recognized that early detection of central $\mathrm{CH}$ also enables early diagnosis of MPHD, which are potentially life-threatening in case of adrenocorticotrophic hormone (ACTH) deficiency and growth hormone deficiency (GHD), primarily because of severe hypoglycemia (5).

While characteristics of primary $\mathrm{CH}$ patients have been described extensively, studies in central $\mathrm{CH}$ patients are scarce $(4,8)$. Clinical characteristics of MPHD patients can be retrieved in part from studies on pituitary stalk interruption syndrome (PSIS) (9). However, not all central $\mathrm{CH}$ patients with MPHD have PSIS. Consequently, these patients and patients with isolated central $\mathrm{CH}$ are not included in PSIS studies.

Neonatal screening in the Netherlands detects both primary and central $\mathrm{CH}$, and consists of primary $\mathrm{T} 4$ measurement, followed by TSH measurement in the lowest $20 \%$ of T4 concentrations. To reduce the number of falsepositives due to T4-binding globulin (TBG) deficiency, TBG measurement in the lowest $5 \%$ of $\mathrm{T} 4$ concentrations was added in 1995 (7). This enables calculation of the T4/TBG ratio, providing an estimation of the FT4 concentration. Evaluation studies show the Dutch three-step approach effectively detects primary and central $\mathrm{CH}$, resulting in the highest prevalence of central $\mathrm{CH}$ worldwide (1 in 16 404) (7).

Although guidelines acknowledge the value of neonatal central $\mathrm{CH}$ screening, the vast majority of neonatal screening programs detect only primary $\mathrm{CH}(5$, 10). Yet, a pilot study for a neonatal screening program aiming at central $\mathrm{CH}$ detection was performed recently in Argentina, and the risk of not detecting central $\mathrm{CH}$ early has gained attention $(11,12)$. In balancing the pros and cons of central $\mathrm{CH}$ screening, the clinical characteristics of early-detected patients are an important consideration. We performed a cross-sectional study in central $\mathrm{CH}$ patients identified by the Dutch neonatal screening over a 20-year period; our objective was to report on the clinical, endocrine, neuroradiological and genetic characteristics of these patients.

\section{Subjects and methods}

\section{Patient recruitment}

Children with an abnormal neonatal $\mathrm{CH}$ screening result are registered in a national database founded by the Netherlands Organization for Applied Scientific Research (TNO). Permission to use this database was obtained from the Privacy Committee of the Dutch CH Screening Board. All central CH patients born between 1 January 1995 and 1 January 2015 and detected through neonatal screening were invited to participate in the study (Supplementary File 1 , see section on supplementary materials given at the end of this article). The study protocol was approved by the local medical ethics committee of Amsterdam UMC, location AMC. All participants gave informed consent for medical chart review and, if applicable, physical examination during the study visit. Written permission was obtained from patients $\geq 12$ years and from both parents for patients younger than 18 years.

\section{Data collection}

Medical charts were reviewed for data on the medical history, endocrine function testing, neuroimaging and genetic analysis. A structured interview was conducted with one or both parents, and a physical examination was performed. Standard deviation scores (SDS) for current height were calculated using the Dutch reference data from the Growth Analyzer VE (Rotterdam, the Netherlands). SDS for birth weight and length were calculated with the Niklasson reference standards (13). To assess growth, we compared current height-SDS with target height (TH)-SDS for all isolated central $\mathrm{CH}$ patients, and GHD patients who had been treated with GH for at least three years.

To confirm the diagnosis of central $\mathrm{CH}$, FT4 concentrations before treatment and results from thyrotropin-releasing hormone (TRH) stimulation tests were reviewed using the local hospital's reference intervals. During TRH testing, TSH concentrations are measured at fixed time points after intravenous TRH administration (standard dosage is $10 \mu \mathrm{g} / \mathrm{kg}$, max $200 \mu \mathrm{g}$ ). Healthy infants show a type 0 response, with a TSH peak $>15 \mathrm{mIU} / \mathrm{L}$ in the first $30 \mathrm{~min}$, returning to baseline within 3 hours (14). A type 2 response is characterized by deficient TSH increase, and is often seen in patients with isolated central $\mathrm{CH}$; a type 3 response, i.e., slightly delayed but excessive TSH increase followed by a delayed decrease, is frequently seen in MPHD patients (14). 
The assessment of additional pituitary hormone deficiencies and MRI studies are described in Supplementary File 1.

\section{Genetic analysis}

Isolated central $\mathrm{CH}$ patients without a prior confirmed genetic diagnosis were offered genetic (re-)testing with a targeted gene panel, including the following genes: ANOS1, BMP4, CHD7, FGF8, FGFR1, GLI2, HESX1, IGSF1, IRS4, LHX3, LHX4, OTX2, PAX6, POU1F1, PROK2, PROKR2, PROP1, SHH, SOX2, SOX3, TBL1X, TRH, TRHR and TSHB, using Next Generation Sequencing (NGS). NGS was performed with MiSeq, using MiSeq v2 reagents; $2 \times 150$ bp reads (Illumina, Inc., San Diego, USA). Nimblegen SeqCap EZ Choice (Roche Diagnostics) was used for target enrichment. Since a genetic diagnosis is only established in 5-10\% of MPHD patients, and mostly in patients with syndromic forms, genetic (re-)testing was not performed in MPHD patients (15). However, in some patients, genetic analysis had been previously performed by the treating pediatrician $(n=18)$; these results are also reported.

\section{Statistical analysis}

Data are reported as mean \pm S.D. or median and range, depending on the distribution of data. Comparisons between MPHD patients and isolated central $\mathrm{CH}$ patients were made using $t$-tests for normally distributed data and Mann-Whitney $U$ tests for data that were not-normally distributed. Categorical characteristics were compared using the Chi-squared test or Fisher's exact test. In current guidelines, $\mathrm{CH}$ severity is classified based on pre-treatment plasma FT4 concentrations, but neonatal FT4 concentrations are known to differ from day to day $(10,16)$. Multiple linear regression was therefore used to compare pre-treatment FT4 concentrations between patient groups, including age in days to correct for the day of measurement. Differences were considered significant in case of two-sided $P$-values $<0.05$. Analyses were performed with RStudio version 3.6.1 (2019-07-05); graphs were designed using ggplot2 $(17,18)$.

\section{Results}

During the study period, 3813329 children were born of whom $7705(0.2 \%)$ died before the neonatal screening could be performed. Of the remaining children, $99.7 \%$ participated in the neonatal screening. Central $\mathrm{CH}$ was diagnosed in 154 children, of whom 94 (61\%) with MPHD and 60 (39\%) with isolated central CH (Fig. 1). Permanent central $\mathrm{CH}$ was diagnosed in 148 patients, resulting in a calculated incidence of 1:25 642. Six cases were transient (five isolated central $\mathrm{CH}$, one MPHD). Of these, three isolated cases were due to maternal Graves

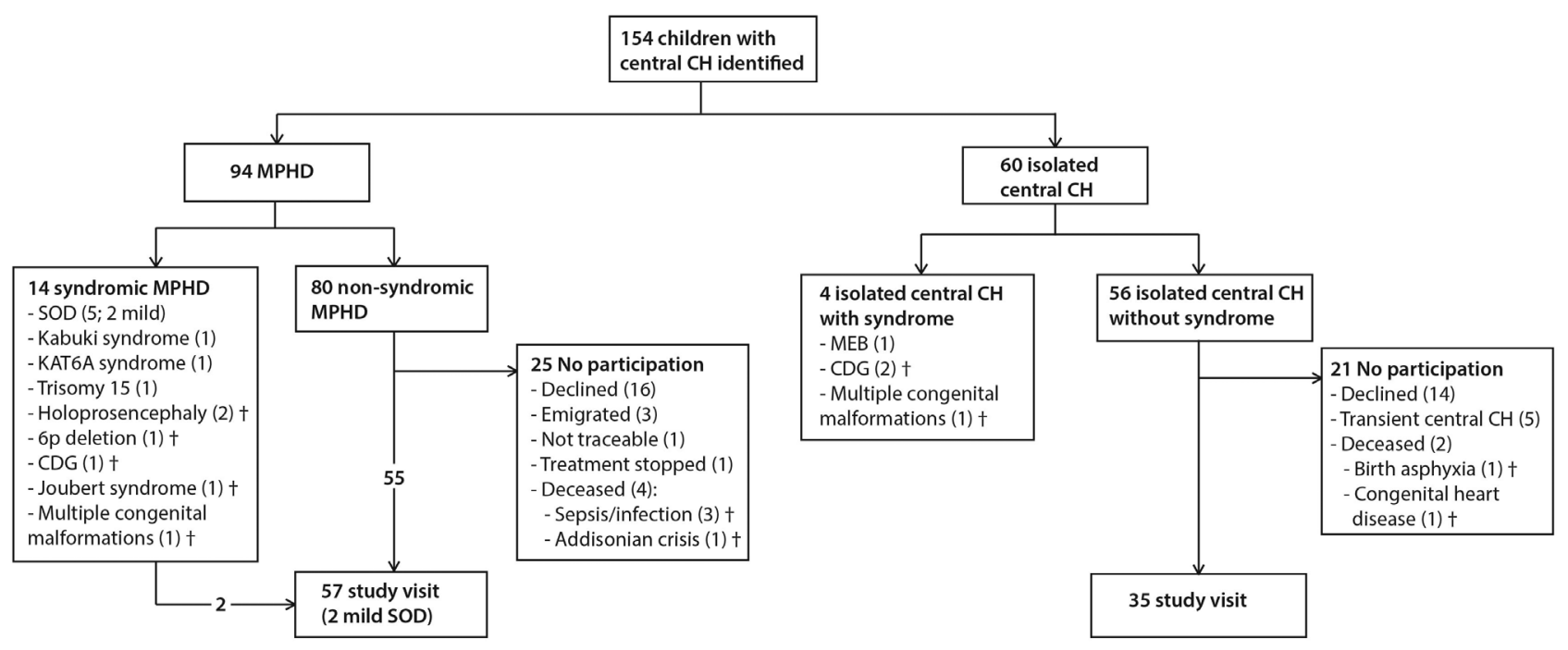

\section{Figure 1}

Patients with central CH identified by the Dutch neonatal screening within a 20-year period. CDG, congenital disorder of glycosylation; $\mathrm{CH}$, congenital hypothyroidism; KAT6A, K acetyltransferase 6A; MEB, muscle-eye-brain disease; MPHD, multiple pituitary hormone deficiencies; SOD, septo-optic dysplasia. $t$, deceased patient. 
disease, which is a well-known cause of transient isolated central $\mathrm{CH}$ (19). The remaining three patients could discontinue replacement therapy in childhood; no cause was identified.

Fifteen patients had died and have been reported previously (3). In summary, the high mortality rate could be explained by congenital malformations/syndromes, early infection and birth asphyxia. In only one MPHD patient the cause of death was attributed to pituitary insufficiency (Addisonian crisis).

After excluding deceased patients $(n=15)$, severe syndromic patients $(n=7)$ and patients with transient central CH ( $n=6), 126$ eligible patients remained. Ninetytwo patients (57 MPHD), originating from 89 families, gave permission for medical chart review. From three families, two siblings were included; all had a genetic form of isolated central CH. No syndromes were present among included patients, except for two patients with mild septooptic dysplasia. In one of these patients, the diagnosis septo-optic dysplasia was already made prenatally, with a hospital admission directly after birth. The other patient was admitted for sepsis-like illness on day 4, but the diagnosis was made only after screening results suggestive for central $\mathrm{CH}$ and subsequent endocrine evaluation. Both patients suffer from severely impaired vision in at least one eye.

\section{Early signs and symptoms}

Thirty-six MPHD patients (63\%) and 30 isolated central $\mathrm{CH}$ patients $(86 \%)$ were born after an uneventful pregnancy, i.e., without any reported maternal health problems or medication. For the remaining mothers, health problems were mainly pregnancy-related, for example, pregnancyinduced hypertension and gestational diabetes. An overview of perinatal and clinical characteristics is presented in Table 1.

Hypoglycemia, hyperbilirubinemia and sepsis-like illness occurred more frequently in MPHD patients, with lower glucose concentrations during hypoglycemia in MPHD patients than in isolated central $\mathrm{CH}$ patients (mean difference $-0.9 \mathrm{mmol} / \mathrm{L}, 95 \% \mathrm{CI}-0.3$ to $-1.5 \mathrm{mmol} / \mathrm{L}$, $P<0.001)$. For hyperbilirubinemia, phototherapy sufficed in all patients. Three MPHD patients had neonatal cholestasis which resolved with adequate hormone replacement therapy (consisting of levothyroxine in one patient, and the combination of levothyroxine and hydrocortisone in the other two patients).

Sixty-one patients were hospitalized before screening results were known. During these admissions, central $\mathrm{CH}$ was diagnosed in only three patients (5\%). In the other $95 \%$, the diagnosis was made only after screening results were reported. In 79 patients $(86 \%)$ treatment was started in the first month of life.

\section{Biochemical characteristics}

Pre-treatment FT4 concentrations were significantly lower in MPHD patients than in isolated central $\mathrm{CH}$ patients (mean difference $-1.7 \mathrm{pmol} / \mathrm{L}, 95 \%$ CI -2.7 to -0.7 , $P<0.001)$. TRH testing was performed in 65 patients. Twenty-six patients had a type 2 response; $81 \%$ of them had isolated central $\mathrm{CH}$. Thirty-seven patients had a type 3 response; 95\% of them had MPHD. A type 0 response (physiological) was seen in one isolated central $\mathrm{CH}$ patient. In one patient the test failed due to technical reasons. TRH test results $(n=60)$ are shown in Fig. 2.

\section{Other pituitary hormone deficiencies and growth}

The frequency of pituitary hormone deficiencies other than TSH is shown in Table 1. Various combinations of pituitary hormone deficiencies were seen among MPHD patients: $\mathrm{TSH}+\mathrm{ACTH}(n=2 ; 4 \%) ; \mathrm{TSH}+\mathrm{GH} \quad(n=8 ; 14 \%)$; $\mathrm{TSH}+\mathrm{ACTH}+\mathrm{GH}(n=27 ; 47 \%)$, and TSH+ACTH+GH+LH/ FSH $(n=20 ; 35 \%)$. Twenty-nine MPHD patients were too young to determine the presence of gonadotropin deficiency (GD). Assessment and outcome of additional pituitary hormone deficiencies in MPHD patients are described in Supplementary File 1.

To assess growth, the difference between current height-SDS and TH-SDS was calculated for all isolated central $\mathrm{CH}$ patients with an available $\mathrm{TH}(n=34)$. Of these, 32 patients (94\%) had a current height within $\mathrm{TH}$ range. Mean difference between current height-SDS and TSH-SDS was $-0.3 \pm 1.0$ s.D.

Among GHD patients receiving GH for at least 3 years, $\mathrm{TH}$ was available for 48 patients (median duration of $\mathrm{GH}$ treatment 10.5 years). Mean difference between current height-SDS and TH-SDS was $-0.11 \pm 0.9$ in these patients; 47 (98\%) had a current height within $\mathrm{TH}$ range.

\section{Imaging}

Brain MRI results from 73 patients were available. In 23 cases (19 isolated central $\mathrm{CH}$ ), no abnormalities were found. MRI results of MPHD patients $(n=54)$, including the various combinations of pituitary abnormalities, are shown in Fig. 3. 
Table 1 Clinical characteristics of 92 patients with central CH born between 1 January 1995 and 1 January 2015. Data are presented as $n(\%)$, median (range) or mean ( \pm S.D.). Dried blood spot (DBS) concentrations are derived from the first neonatal screening assessment.

\begin{tabular}{|c|c|c|c|}
\hline & Central CH as part of MPHD $(n=57)$ & Isolated central CH $(n=35)$ & P-value \\
\hline \multicolumn{4}{|l|}{ Demographic data } \\
\hline Age at follow-up (years) & $10.1(3-22)$ & $13.0(4-24)$ & 0.51 \\
\hline Male (\%) & $41(72 \%)$ & $32(91 \%)$ & 0.05 \\
\hline \multicolumn{4}{|l|}{ Perinatal data } \\
\hline Gestational age & $39^{2 / 7}\left(34^{1 / 7}-42^{3 / 7}\right)^{*}$ & $40^{5 / 7}\left(34^{2 / 7}-42^{2 / 7}\right)$ & 0.005 \\
\hline Birthweight (g) & $3199 \pm 594^{*}$ & $3684 \pm 655$ & $<0.001$ \\
\hline Birthweight, S.D. & $-0.4 \pm 1.1^{*}$ & $0.3 \pm 1.3$ & 0.02 \\
\hline Breech position at delivery & $17(30 \%)$ & $0(0 \%)$ & $<0.001$ \\
\hline Cesarean section & $14(25 \%)$ & $4(11 \%)$ & 0.20 \\
\hline Apgar $<6$ at 5 min & $5(9 \%)$ & $0(0 \%)$ & 0.15 \\
\hline Birth trauma & $11(19 \%)$ & $0(0 \%)$ & 0.006 \\
\hline \multicolumn{4}{|l|}{ Clinical features } \\
\hline Micropenis in males & $18(45 \%)$ & $0(0 \%)$ & $<0.001$ \\
\hline Cryptorchidism in males & $2(5 \%)$ & $1(3 \%)$ & 1 \\
\hline Umbilical hernia & $4(7 \%)$ & $3(9 \%)$ & 1 \\
\hline \multicolumn{4}{|l|}{ Neonatal health problems } \\
\hline Hypoglycemia & $30(55 \%)^{\dagger}$ & $5(14 \%)$ & $<0.001$ \\
\hline Glucose during hypoglycemia (mmol/L) & $1.2 \pm 0.8$ & $2.1 \pm 0.5$ & 0.008 \\
\hline Feeding problems & $33(\overline{6} 0 \%)^{\dagger}$ & $13(37 \%)$ & 0.06 \\
\hline Hypothermia & $22(39 \%)$ & $8(23 \%)$ & 0.18 \\
\hline Hyperbilirubinemia & $30(53 \%)$ & $5(14 \%)$ & $<0.001$ \\
\hline Sepsis-like illness & $24(42 \%)$ & $6(17 \%)$ & 0.02 \\
\hline $\begin{array}{l}\text { Hospitalized prior to abnormal neonatal } \\
\text { screening result }\end{array}$ & $50(88 \%)$ & $11(31 \%)$ & $<0.001$ \\
\hline Discharged without a diagnosis of central $\mathrm{CH}$ & $28(49 \%)$ & $7(20 \%)$ & 0.01 \\
\hline $\begin{array}{l}\text { Diagnosis of (central) } \mathrm{CH} \text { prior to abnormal } \\
\text { neonatal screening result }\end{array}$ & $3(5 \%)$ & $0(0 \%)$ & 0.29 \\
\hline \multicolumn{4}{|l|}{ Screening results and age at diagnosis } \\
\hline DBS T4 concentration (nmol/L) & $54(8-153)$ & $60(20-145)$ & 0.79 \\
\hline DBS T4, S.D. & $-2.3(-4.3$ to -0.4$)$ & $-2.4(-3.8$ to -0.16$)$ & 0.35 \\
\hline DBS TSH concentration $<3 \mathrm{mU} / \mathrm{L}$ & $34(63 \%)^{\ddagger}$ & $17(34 \%)^{\S}$ & 0.33 \\
\hline DBS T4/TBG ratio (abnormal if $<17$ ) & $9.0(2.9-16.1)^{\ddagger}$ & $8.0(4.2-16.8)^{\S}$ & 0.42 \\
\hline $\begin{array}{l}\text { Venous FT4 concentration (pmol/L) at first } \\
\text { diagnostic measurement }\end{array}$ & $8.7 \pm 2.1$ & $10.4 \pm 2.4$ & $<0.001$ \\
\hline Age at first diagnostic measurement (days) & $13(2-135)$ & $14(5-58)$ & 0.22 \\
\hline Age at start of treatment (days) & $17(2-135)$ & $21(7-162)$ & 0.13 \\
\hline \multicolumn{4}{|l|}{ Pituitary hormone deficiencies } \\
\hline Growth hormone deficiency & $55(96 \%)$ & $1(3 \%)^{a}$ & NA \\
\hline ACTH deficiency & $49(86 \%)$ & $0(0 \%)$ & NA \\
\hline Gonadotropin deficiency & $20(74 \%)^{\|}$ & $0(0 \%)$ & NA \\
\hline
\end{tabular}

aPartial growth hormone deficiency was diagnosed in one patient with IGSF1 deficiency syndrome. ${ }^{*} n=56 ;{ }^{\dagger} n=55 ;{ }^{\ddagger} n=54 ;{ }^{\circledR} n=34 ;{ }^{\circledR} n=28 ;{ }^{\|} n=27$. $\mathrm{ACTH}$, adrenocorticotropic hormone; $\mathrm{CH}$, congenital hypothyroidism; DBS, dried blood spot; MPHD, multiple pituitary hormone deficiencies; NS, neonatal screening; T4, thyroxine; TBG, thyroxine-binding globulin; TSH, thyrotropin.

\section{Genetic analysis}

Genetic analysis had already been performed in 22 isolated central $\mathrm{CH}$ patients, and was performed in 10 additional patients for this study. The three remaining patients refused genetic testing. In $91 \%$ of tested patients, we found variants in genes associated with isolated central $\mathrm{CH}$, including eight novel variants (four IGSF1; three TBL1X; one IRS4). All identified variants were pathogenic, except for two novel variants (TBL1X and IGSF1), and one known IGSF1 variant (Table 2) (20). In silico prediction of the novel variants of unknown significance suggested pathogenicity. The TBL1X variant was predicted to cause abnormal protein splicing and possibly a frame-shift mutation, and was de novo (mother did not carry the variant). The IGSF1 variant 


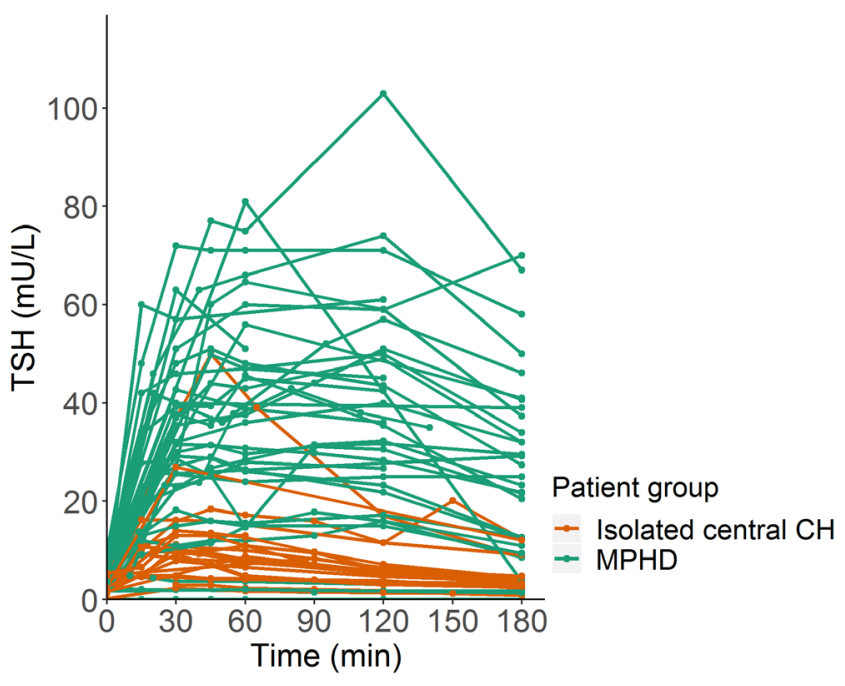

Figure 2

TSH concentrations during TRH tests in children with central $\mathrm{CH}(n=60)$. $\mathrm{CH}$, congenital hypothyroidism; MPHD, multiple pituitary hormone deficiencies.

caused an amino acid substitution probably leading to abnormal protein function. The healthy mothers of the two patients with the IGSF1 variant were not willing to undergo genetic analysis themselves. No male siblings were present.

Among MPHD patients, genetic analysis had been performed prior to our study in 18 patients. The targeted gene panel for central $\mathrm{CH}$, as used in the current study, was

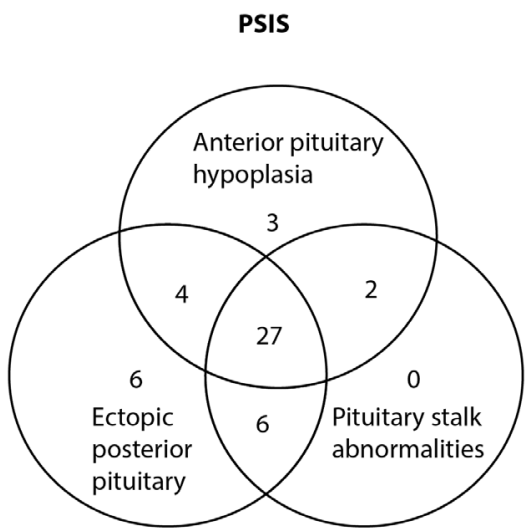

Other abnormalities

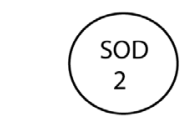

No abnormalities

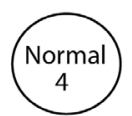

Figure 3

The incidence of pituitary abnormalities in patients with central congenital hypothyroidism and multiple pituitary hormone deficiencies (54 MRI scans available). Two patients (one complete PSIS; one SOD) also had optic nerve hypoplasia. PSIS, pituitary stalk interruption syndrome; SOD, septo-optic dysplasia. performed in 10 patients. Abnormalities were found in two patients. One patient was heterozygous for a POU1F1 variant (c.143T $>$ G, p.Val48Gly); this variant was not present in the patient's healthy parents and was classified as likely pathogenic. In the same patient, an FGFR3 variant of unknown significance was identified (c.1388A $>$ G, p.Tyr463Cys), which was present in patient's healthy father as well. In the second patient, a $\mathrm{SOX} 3$ variant of unknown significance was identified (c.696C>A, p.(?)). Whether this variant was de novo could not be retrieved from medical charts.

In the remaining eight patients, gene analysis focused on one or several genes associated with hypopituitarism or central CH (HESX1: five patients; PROP1: two patients; TBL1X: two patients; LHX3: one patient; SOX2: one patient; IRS4: one patient). No abnormalities were found in these patients.

\section{Discussion}

In this study, we describe the clinical characteristics of 92 patients with central $\mathrm{CH}$, both isolated and as part of MPHD, after early detection in the Dutch neonatal screening program during a 20 -year period. This is the largest group of early-detected central $\mathrm{CH}$ patients reported on to date, providing insight into the yield of a central $\mathrm{CH}$ screening program. The incidence of central $\mathrm{CH}$ in the current study (1:25 642) is similar to that previously reported in the Netherlands (1:25000 for the period 19811990) (21). The Dutch central CH incidence rate thus remained stable, but is higher than in previous studies on T4-based screening programs in Buenos Aires and Indiana $(4,11)$. This might be due to truly lower incidences in these countries. However, an alternative explanation is that these programs use more strict cut-offs: in Buenos Aires a T4 cut-off of $4.5 \mu \mathrm{g} / \mathrm{dL}(58 \mathrm{nmol} / \mathrm{L} ;-2.3$ s.D.) was used, in Indiana the cut-off was $5 \mu \mathrm{g} / \mathrm{dL}$ ( $64 \mathrm{nmol} / \mathrm{L} ;-2.0$ S.D.). The Dutch screening program does not use a fixed T4 cut-off. Instead, an additional TSH measurement is performed when T4 concentration is <-0.8 S.D. of the daily mean (lowest 20\%), and both TSH and TBG are measured when T4 concentration is <-1.6 S.D. (lowest $5 \%$ ). While newborns with a $\mathrm{T} 4<-3.0$ s.D. are immediately referred, newborns with a $\mathrm{T} 4$ between -0.8 and -3.0 s.D. are referred based on TSH and TBG concentrations (22). If TSH is inappropriately low and the T4/TBG ratio does not imply (relative) TBG deficiency, the screening result is considered inconclusive, and a second screening is performed. As a result of this unique program, a higher 
Table 2 Results from genetic analysis in 32 patients with isolated central CH, born in the period 1 January 1995 to 1 January 2015.

\begin{tabular}{|c|c|c|}
\hline Gene & Patients, $\boldsymbol{n}(\%)$ & Nucleotide alteration \\
\hline IGSF1 & $\begin{array}{l}17(53 \%) ; \\
15 \text { families }\end{array}$ & $\begin{array}{l}\text { c. } 1847 \mathrm{G}>\mathrm{A}^{\dagger} \\
\text { c. } 1981 \mathrm{G}>\mathrm{A}(n=2)^{\ddagger} \\
\text { c. } 2267 \mathrm{G}>\mathrm{A}+\mathrm{c} .2278 \mathrm{G}>\mathrm{T} \\
\text { c. } 2388 \mathrm{del}^{\dagger} \\
\text { c. } 2248 \mathrm{delG}(n=3 ; 2 \text { families }) \\
\text { c. } 3032 \mathrm{delinsTT} \\
\text { c. } 3049 \mathrm{C}>\mathrm{T}(n=2 ; 1 \text { family) } \\
\text { c. } 3416 \mathrm{G}>\mathrm{T}^{\dagger, \ddagger} \\
\text { c. } 3565 \mathrm{C}>\mathrm{T} \\
\text { c. } 3691 \mathrm{~T}>\mathrm{G} \\
\text { c. } 3767-1 \mathrm{G}>\mathrm{A} \\
\text { c. }(?-1)(4026+?) \text { del }{ }^{\dagger} \\
\text { c. } 328-\mathrm{kb} \text { deletion, } \operatorname{arr} \text { Xq26.1q26.2 }\end{array}$ \\
\hline IRS4 & $\begin{array}{l}5(16 \%) ; \\
4 \text { families }\end{array}$ & $\begin{array}{l}\text { c. } 1772 \text { dup }(n=2) \\
\text { c. } 554 \mathrm{C}>\mathrm{A}^{\dagger} \\
\text { c. } 643 \mathrm{G}>\mathrm{T}(n=2 ; 1 \text { family })\end{array}$ \\
\hline$T B L 1 X$ & $5(16 \%)$ & $\begin{array}{l}\text { c. } 1152 \mathrm{del}^{\dagger} \\
\text { c. } 1246 \mathrm{~A}>\mathrm{T} \\
\text { c. } 1510 \mathrm{C}>\mathrm{T} \\
\text { c. } 705 \mathrm{G}>\mathrm{A}^{\dagger, \ddagger} \\
\text { c. } 357+1 \mathrm{G}>\mathrm{A}^{\dagger}\end{array}$ \\
\hline TSHB & $1(3 \%)$ & c.373delT \\
\hline $\begin{array}{l}T R H-R \\
\text { No genetic cause found }\end{array}$ & $\begin{array}{l}1(3 \%) \\
3(9 \%)\end{array}$ & c. $49 \mathrm{C}>\mathrm{T}$ \\
\hline
\end{tabular}

\begin{tabular}{l} 
Amino acid alteration \\
\hline p.Trp616* \\
p.Gly661 Arg \\
p.Arg756His + Glu760* \\
p.Gly797Valfs*4 \\
p.Glu750Lysfs*28 \\
p.Gly1011Valfs*14 \\
p.Gln1017* \\
p.Cys1139Phe \\
p.Arg1189* \\
p.Cys1231Gly \\
a \\
b \\
c \\
p.Lys592Glnfs*12 \\
p.Ser185* \\
p.Gly215* \\
p.Phe385Leufs*50 \\
p.Asn365Tyr \\
p.His453Tyr \\
p.Val235= \\
p.(?) \\
p.Cys125Valfs*10 \\
p.Arg17*
\end{tabular}

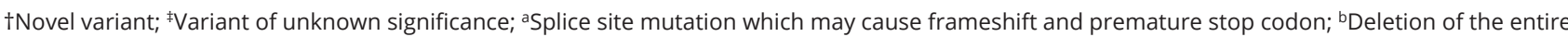
coding sequence; 'Decreased membrane expression and glycosylation as described by Joustra et al. (20).

number of central $\mathrm{CH}$ patients is detected, including milder cases with $\mathrm{T} 4$ concentrations which are on average higher compared to cases from Buenos Aires and Indiana (Table 1). It also explains why the proportion of isolated central $\mathrm{CH}$ patients compared to MPHD is higher than in previous studies. Isolated central $\mathrm{CH}$ patients have on average higher pre-treatment FT4 concentrations than MPHD patients, and are thus detected more easily in the Dutch screening program.

A male predominance was seen in the entire group, in line with previous studies $(7,23)$. For isolated central $\mathrm{CH}$ this can be explained by associated X-linked genes IGSF1, IRS4 and TBL1X $(20,24,25)$. While male predominance has also been described in patients with congenital hypopituitarism or PSIS (55-85\%), the explanation is less clear for MPHD patients $(9,26,27)$ Variants of X-linked genes in congenital MPHD (SOX3; EIF2S3) are very rare. Overall, a genetic cause is found in only $5-10 \%$ of MPHD patients (15).

Most MPHD patients (88\%) were hospitalized before the neonatal screening results became known, for example, for hypoglycemia or sepsis-like illness. Hypoglycemia and sepsis-like illness are known effects of
ACTH deficiency, may be aggravated by concomitant GHD and can be life-threatening if left untreated. Neonatal cholestasis is another known manifestation of MPHD (28). It is attributed to both cortisol deficiency and GHD, as glucocorticoids increase bile flow and GH is involved in the synthesis and excretion of bile acids $(28,29)$. The role of central $\mathrm{CH}$ in neonatal cholestasis in MPHD patients is unclear. The low prevalence of neonatal cholestasis in our study may be related to the early start of hormone treatment, particularly of hydrocortisone.

Despite neonatal hospitalization in 61 patients, central $\mathrm{CH}$ was diagnosed purely on clinical grounds in only three of them (5\%). Most patients were even discharged, and readmitted because of the abnormal screening result. These results emphasize the importance of central $\mathrm{CH}$ screening. To date, central $\mathrm{CH}$ is the only pituitary hormone deficiency suitable for a neonatal screening program. Detection through screening led to early diagnosis and treatment of MPHD, and MPHD patients started thyroxine at a median age of 17 days. However, when central $\mathrm{CH}$ is not detected by neonatal screening, a mean age at endocrine consultation of 16 months is reported (4). The fact that central CH is missed 
despite early symptoms has been reported in smaller studies before. Mehta et al described 54 central $\mathrm{CH}$ patients of whom only $28 \%$ were diagnosed during the neonatal period, although $72 \%$ had neonatal problems (23). Similar results are seen in PSIS patients (9). These cases, missed despite early symptoms, highlight the importance of neonatal screening for central $\mathrm{CH}$. They also underline the need for improving awareness of this rare disorder among clinicians.

The diagnosis of isolated central $\mathrm{CH}$ was genetically confirmed in the majority of patients. IGSF1 variants were seen in 53\%. IGSF1 deficiency currently is the most common genetic cause of isolated central $\mathrm{CH}$; in a previous Japanese study IGSF1 variants were identified in $38 \%$ of patients $(20,30)$. The current study suggests an even higher proportion of patients with IGSF1 deficiency as a cause of isolated central $\mathrm{CH}$.

The value of TRH stimulation testing in diagnosing central $\mathrm{CH}$ is controversial (23). Although the majority of central $\mathrm{CH}$ patients show an abnormal response, a normal response does not rule out central hypothyroidism. The role of TRH testing in diagnosing central hypothyroidism is therefore considered 'modest' $(23,31)$. Van Tijn et al. performed a study in 15 infants with central $\mathrm{CH}$ and observed an abnormal TSH response in all patients (14). They concluded that especially a type 3 response may help distinguishing neonates with central $\mathrm{CH}$ from infants with a false-positive screening result. In the current study, a type 3 response was almost exclusively seen in MPHD patients, which emphasizes the value of TRH testing when central $\mathrm{CH}$ with MPHD is suspected. Because only central $\mathrm{CH}$ patients were included, TRH testing results could not be compared with healthy neonates.

ACTH deficiency was present in 49 (86\%) MPHD patients and was diagnosed within the first 6 months of life in 44 (90\%) patients. It is important to realize that in patients with pituitary malformations, ACTH deficiency may emerge later in life (32). In one patient ACTH deficiency was diagnosed by performing a low dose ACTH test at the age of 14 years, while a neonatal glucagon stimulation test and early morning serum cortisol measurements throughout childhood were normal. This emphasizes the need to continue monitoring patients, even into adulthood.

The majority of MPHD patients (96\%) had GHD. Previous studies show that GHD is present in $100 \%$ of PSIS patients, whereas central $\mathrm{CH}$ is reported in $48-80 \%$ of PSIS patients $(9,33)$. The high GHD prevalence found in the current study indicates that GHD is almost always present in MPHD patients identified through central
$\mathrm{CH}$ screening. GHD was diagnosed in one patient with isolated central $\mathrm{CH}$ due to IGSF1 deficiency syndrome. Transient partial GHD has been described in 14\% of IGSF1 deficiency patients (20).

Among MPHD patients old enough for pubertal assessment, GD was present in 20 patients (74\%). This corresponds with previous studies reporting GD in $66-80 \%$ of patients with PSIS and MPHD $(9,34)$. A previous study on congenital GD raised the question whether boys with MPHD and a normal penis could still have GD (35). Five GD patients did not have a history of micropenis or cryptorchidism, implying that normal male genitalia early in life does not exclude GD. In addition, Rottembourg et al reported that two of 11 PSIS patients with GD had a normal penis (34). On the other hand, the presence of micropenis does not always indicate GD; it has also been observed in (isolated) GHD (36). In our study, one MPHD patient with a micropenis at birth had a spontaneous onset of puberty at the age of 11 .

Our study has both strengths and limitations. A strength is the inclusion of a large group of early-detected central $\mathrm{CH}$ patients, originating from a nationwide sample. The use of a national database and the long follow-up period enabled us to provide a complete overview of patients and their definitive diagnoses. Moreover, we provide detailed clinical data of MPHD and isolated central $\mathrm{CH}$ patients. Previous studies in MPHD often focused on specific groups, for example, PSIS patients, while studies on isolated central $\mathrm{CH}$ are even more scarce, except for studies regarding the IGSF1 deficiency syndrome $(9,20)$.

A limitation of our study is that, as patients were diagnosed and treated in different hospitals, various laboratory assays were used, which is especially important for the neonatal FT4 measurement. In addition, included patients were diagnosed in a 20-year period, during which MRI techniques improved considerably. Finally, although we obtained all data available for 92 patients, no data could be reviewed for 47 patients, and a certain degree of selection bias cannot be excluded. The retrospective nature of most assessments performed in this study can also be considered a limitation.

In conclusion, we provide an overview of the yield of 20 years of neonatal screening for central $\mathrm{CH}$ in the Netherlands, which may be valuable for countries considering to adjust their $\mathrm{CH}$ screening program to include the detection of central $\mathrm{CH}$. In 91\% of isolated central $\mathrm{CH}$ patients, the diagnosis was genetically confirmed by identification of IGSF1, TBL1X, IRS4, TSHB or $T R H-R$ variants. Pituitary abnormalities were not seen in isolated central $\mathrm{CH}$ patients, while the majority of 
MPHD patients had pituitary abnormalities compatible with PSIS. Most MPHD patients, and one-third of isolated central $\mathrm{CH}$ patients, were hospitalized in the neonatal period for severe hypoglycemia and sepsis-like illness. However, despite these hospital admissions almost none of the patients were diagnosed clinically. Instead, central $\mathrm{CH}$ was diagnosed only after the neonatal screening result turned out to be abnormal, often even after the patient had already been discharged. This illustrates the importance of a T4-based neonatal screening program to ensure early diagnosis of central $\mathrm{CH}$. It also highlights the need to improve awareness of this rare disorder among clinicians since most patients, especially in case of MPHD, were not recognized despite the presence of classic symptoms such as hypoglycemia, jaundice and micropenis.

\section{Supplementary materials}

This is linked to the online version of the paper at https://doi.org/10.1530/ EJE-20-0833.

\section{Declaration of interest}

$\mathrm{N}$ Z-S has received a grant from Pfizer to support this investigatorinitiated study (tracking number WI219179). Pfizer was not involved in patient recruitment, data collection, data analysis or preparation of the manuscript. All other authors declare no competing interests.

\section{Funding}

Support for this investigator-initiated study was provided by Pfizer (tracking number WI219179).

\section{Author contribution statement}

A S P V T and N Z-S contributed equally to this work. N Z-S, A S P V T, P H V and E F designed the study. J C N acquired data, designed the statistical plan, analyzed and interpreted data, and wrote the manuscript. N Z-S supervised the study, interpreted data, and critically reviewed the manuscript. P H extracted data and revised the manuscript. A S P v T supervised the study, interpreted data, and critically reviewed the manuscript. E F critically reviewed the manuscript. A S P v T and N Z-S had full access to all of the study data and takes responsibility for the integrity of the data and the accuracy of the data analysis.

\section{Acknowledgement}

The authors would like to thank Brenda Wiedijk (Amsterdam UMC, location $\mathrm{AMC}$ ) for her help with patient recruitment and collection of the medical charts.

\section{References}

1 Persani L, Brabant G, Dattani M, Bonomi M, FeldtRasmussen U, Fliers E, Gruters A, Maiter D, Schoenmakers N \& van Trotsenburg ASP. 2018 European Thyroid Association (ETA) guidelines on the diagnosis and management of central hypothyroidism. European Thyroid Journal 20187 225-237. (https:// doi.org/10.1159/000491388)

2 Schoenmakers N, Alatzoglou KS, Chatterjee VK \& Dattani MT. Recent advances in central congenital hypothyroidism. Journal of Endocrinology 2015227 R51-R71. (https://doi.org/10.1530/JOE-150341)

3 Zwaveling-Soonawala N, Naafs JC, Verkerk PH \& van Trotsenburg ASP. Mortality in children with early-detected congenital central hypothyroidism. Journal of Clinical Endocrinology and Metabolism 2018103 3078-3082. (https://doi.org/10.1210/jc.201800629)

4 Nebesio TD, McKenna MP, Nabhan ZM \& Eugster EA. Newborn screening results in children with central hypothyroidism. Journal of Pediatrics 2010156 990-993. (https://doi.org/10.1016/j. jpeds.2009.12.011)

5 Ford G \& LaFranchi SH. Screening for congenital hypothyroidism: a worldwide view of strategies. Best Practice and Research: Clinical Endocrinology and Metabolism 201428 175-187. (https://doi. org/10.1016/j.beem.2013.05.008)

6 Kilberg MJ, Rasooly IR, LaFranchi SH, Bauer AJ \& Hawkes CP. Newborn screening in the US may miss mild persistent hypothyroidism. Journal of Pediatrics 2018192 204-208. (https://doi. org/10.1016/j.jpeds.2017.09.003)

7 Lanting CI, van Tijn DA, Loeber JG, Vulsma T, de Vijlder JJ \& Verkerk PH. Clinical effectiveness and cost-effectiveness of the use of the thyroxine/thyroxine-binding globulin ratio to detect congenital hypothyroidism of thyroidal and central origin in a neonatal screening program. Pediatrics 2005116 168-173. (https://doi. org/10.1542/peds.2004-2162)

8 Naafs JC, Vendrig LM, Limpens J, van der Lee HJ, Duijnhoven RG, Marchal JP, van Trotsenburg ASP \& Zwaveling-Soonawala N. Cognitive outcome in congenital central hypothyroidism: a systematic review with meta-analysis of individual patient data. European Journal of Endocrinology 2020182 351-361. (https://doi. org/10.1530/EJE-19-0874)

9 Bar C, Zadro C, Diene G, Oliver I, Pienkowski C, Jouret B, Cartault A, Ajaltouni Z, Salles JP, Sevely A et al. Pituitary stalk interruption syndrome from infancy to adulthood: clinical, hormonal, and radiological assessment according to the initial presentation. PLOS ONE 201510 e0142354. (https://doi.org/10.1371/journal. pone.0142354)

10 Léger J, Olivieri A, Donaldson M, Torresani T, Krude H, van Vliet G, Polak M, Butler G, ESPE-PES-SLEP-JSPE-APEG-APPESISPAE \& Congenital Hypothyroidism Consensus Conference Group. European Society for Paediatric Endocrinology consensus guidelines on screening, diagnosis, and management of congenital hypothyroidism. Hormone Research in Paediatrics 201481 80-103. (https://doi.org/10.1159/000358198)

11 Braslavsky D, Mendez MV, Prieto L, Keselman A, Enacan R, GruneiroPapendieck L, Jullien N, Savenau A, Reynaud R, Brue T et al. Pilot neonatal screening program for central congenital hypothyroidism: evidence of significant detection. Hormone Research in Paediatrics 201788 274-280. (https://doi.org/10.1159/000480293)

12 Cherella CE \& Wassner AJ. Update on congenital hypothyroidism. Current Opinion in Endocrinology, Diabetes, and Obesity 202027 63-69. (https://doi.org/10.1097/MED.0000000000000520)

13 Niklasson A, Ericson A, Fryer JG, Karlberg J, Lawrence C \& Karlberg P. An update of the Swedish reference standards for weight, length and head circumference at birth for given gestational age (19771981). Acta Paediatrica Scandinavica 199180 756-762. (https://doi. org/10.1111/j.1651-2227.1991.tb11945.x)

14 van Tijn DA, de Vijlder JJ \& Vulsma T. Role of the thyrotropinreleasing hormone stimulation test in diagnosis of congenital central hypothyroidism in infants. Journal of Clinical Endocrinology and Metabolism 200893 410-419. (https://doi.org/10.1210/ jc.2006-2656) 
15 Webb EA \& Dattani MT. Understanding hypopituitarism. Paediatrics and Child Health 201525 295-301. (https://doi.org/10.1016/j. paed.2015.03.007)

16 Naafs JC, Heinen CA, Zwaveling-Soonawala N, van der Schoor SRD, van Tellingen V, Heijboer AC, Fliers E, Boelen A \& van Trotsenburg ASP. Age-specific reference intervals for plasma free thyroxine and thyroid stimulating hormone in term neonates during the first two weeks of life. Thyroid 202030 1106-1111 doi:10.1089/ thy.2019.0779.

17 R Core Team. R: A Language and Environment for Statistical Computing. Vienna, Austria: R Foundation for Statistical Computing, 2018.

18 Wickham H. ggplot2: Elegant Graphics for Data Analysis. New York: Springer-Verlag, 2016.

19 Kempers MJ, van Tijn DA, van Trotsenburg AS, de Vijlder JJ, Wiedijk BM \& Vulsma T. Central congenital hypothyroidism due to gestational hyperthyroidism: detection where prevention failed. Journal of Clinical Endocrinology and Metabolism 200388 5851-5857. (https://doi.org/10.1210/jc.2003-030665)

20 Joustra SD, Heinen CA, Schoenmakers N, Bonomi M, Ballieux BE, Turgeon MO, Bernard DJ, Fliers E, van Trotsenburg AS, Losekoot M et al. IGSF1 deficiency: lessons from an extensive case series and recommendations for clinical management. [Erratum appears in J Clin Endocrinol Metab. 2017 Jun 1;102(6):2125; PMID: 28586455]. Journal of Clinical Endocrinology and Metabolism 2016101 1627-1636. (https://doi.org/10.1210/jc.2015-3380)

21 Verkerk PH, Derksen-Lubsen G, Vulsma T, Loeber JG, de Vijlder JJ $\&$ Verbrugge HP. Evaluation of a decade of neonatal screening for congenital hypothyroidism in the Netherlands. Nederlands Tijdschrift voor Geneeskunde 1993137 2199-2205.

22 Stroek K, Heijboer AC, Bouva MJ, van der Ploeg CPB, Heijnen MA, Weijman G, Bosch AM, de Jonge R, Schielen PCJI, van Trotsenburg ASP et al. Critical evaluation of the newborn screening for congenital hypothyroidism in the Netherlands. European Journal of Endocrinology 2020183 265-273. (https://doi.org/10.1530/EJE-19-1048)

23 Mehta A, Hindmarsh PC, Stanhope RG, Brain CE, Preece MA \& Dattani MT. Is the thyrotropin-releasing hormone test necessary in the diagnosis of central hypothyroidism in children. Journal of Clinical Endocrinology and Metabolism 200388 5696-5703. (https:// doi.org/10.1210/jc.2003-030943)

24 Heinen CA, Losekoot M, Sun Y, Watson PJ, Fairall L, Joustra SD, Zwaveling-Soonawala N, Oostdijk W, van den Akker EL, Alders $\mathrm{M}$ et al. Mutations in TBL1X are associated with central hypothyroidism. Journal of Clinical Endocrinology and Metabolism 2016 101 4564-4573. (https://doi.org/10.1210/jc.2016-2531)

25 Heinen CA, de Vries EM, Alders M, Bikker H, ZwavelingSoonawala N, van den Akker ELT, Bakker B, Hoorweg-Nijman G, Roelfsema F, Hennekam RC et al. Mutations in IRS4 are associated with central hypothyroidism. Journal of Medical Genetics $2018 \mathbf{5 5}$ 693-700. (https://doi.org/10.1136/jmedgenet-2017-105113)

26 Nakaguma M, Correa FA, Santana LS, Benedetti AFF, Perez RV, Huayllas MKP, Miras MB, Funari MFA, Lerario AM, Mendonca BB et al. Genetic diagnosis of congenital hypopituitarism by a target gene panel: novel pathogenic variants in GLI2, OTX2 and GHRHR. Endocrine Connections 20198 590-595. (https://doi.org/10.1530/ EC-19-0085)

27 Wang Q, Hu Y, Li G \& Sun X. Pituitary stalk interruption syndrome in 59 children: the value of MRI in assessment of pituitary functions. European Journal of Pediatrics 2014173 589-595. (https://doi. org/10.1007/s00431-013-2214-1)

28 Binder G, Martin DD, Kanther I, Schwarze CP \& Ranke MB. The course of neonatal cholestasis in congenital combined pituitary hormone deficiency. Journal of Pediatric Endocrinology and Metabolism 200720 695-702. (https://doi.org/10.1515/jpem.2007.20.6.695)

29 Braslavsky D, Keselman A, Galoppo M, Lezama C, Chiesa A, Galoppo C \& Bergadá I. Neonatal cholestasis in congenital pituitary hormone deficiency and isolated hypocortisolism: characterization of liver dysfunction and follow-up. Arquivos Brasileiros de Endocrinologia e Metabologia 201155 622-627. (https://doi.org/10.1590/s000427302011000800017)

30 Sugisawa C, Takamizawa T, Abe K, Hasegawa T, Shiga K, Sugawara H, Ohsugi K, Muroya K, Asakura Y, Adachi M et al. Genetics of congenital isolated TSH deficiency: mutation screening of the known causative genes and a literature review. Journal of Clinical Endocrinology and Metabolism 2019104 6229-6237. (https://doi. org/10.1210/jc.2019-00657)

31 Hartoft-Nielsen ML, Lange M, Rasmussen AK, Scherer S, Zimmermann-Belsing T \& Feldt-Rasmussen U. Thyrotropinreleasing hormone stimulation test in patients with pituitary pathology. Hormone Research 200461 53-57. (https://doi. org/10.1159/000075239)

32 Cerbone M \& Dattani MT. Progression from isolated growth hormone deficiency to combined pituitary hormone deficiency. Growth Hormone and IGF Research 201737 19-25. (https://doi. org/10.1016/j.ghir.2017.10.005)

33 Zhang Q, Zang L, Li YJ, Han BY, Gu WJ, Yan WH, Jin N, Chen K, $\mathrm{Du}$ J, Wang XL et al. Thyrotrophic status in patients with pituitary stalk interruption syndrome. Medicine 201897 e9084. (https://doi. org/10.1097/MD.0000000000009084)

34 Rottembourg D, Linglart A, Adamsbaum C, Lahlou N, Teinturier C, Bougnères $\mathrm{P} \&$ Carel JC. Gonadotrophic status in adolescents with pituitary stalk interruption syndrome. Clinical Endocrinology 200869 105-111. (https://doi.org/10.1111/j.1365-2265.2007.03155.x)

35 Braslavsky D, Grinspon RP, Ballerini MG, Bedecarrás P, Loreti N, Bastida G, Ropelato MG, Keselman A, Campo S, Rey RA et al. Hypogonadotropic hypogonadism in infants with congenital hypopituitarism: a challenge to diagnose at an early stage. Hormone Research in Paediatrics 201584 289-297. (https://doi. org/10.1159/000439051)

36 Lee PA, Mazur T, Houk CP \& Blizzard RM. Growth hormone deficiency causing micropenis: lessons learned from a well-adjusted adult. Pediatrics 2018142 e20174168. (https://doi.org/10.1542/ peds.2017-4168)

Received 20 July 2020

Revised version received 08 September 2020

Accepted 30 September 2020 